\title{
Osseointegration of Prostheses on the Stapes Footplate: Evaluation of the Biomechanical Feasibility by Using a Finite Element Model
}

\author{
Marcus Neudert, ${ }^{1}$ Matthias Berner, ${ }^{2}$ Matthias Bornitz, ${ }^{1}$ Thomas Beleites, ${ }^{1}$ Michael Ney, ${ }^{1}$ \\ AND ThOMAS ZaHNerT ${ }^{1}$ \\ ${ }^{1}$ Department of Medicine, Clinic of Otorhinolaryngology, TU Dresden, Fetscherstrasse 74, 01307, Dresden, Germany \\ ${ }^{2}$ Department of Solid State Mechanics, TU Dresden, 01062, Dresden, Germany
}

Received: 15 November 2006; Accepted: 30 July 2007; Online publication: 8 September 2007

\begin{abstract}
Restoration of hearing is one of the main issues of tympanoplasty. Depending on the extent of destruction, the ossicular chain is partially or totally replaced by prostheses. In the unfavorable event of complete ossicular chain destruction with only the stapes footplate remaining in the oval niche, implanting of a columella prosthesis represents the gold standard. Besides ventilation problems, the main causes of unsatisfactory hearing results are dislocation of the prosthesis and poor coupling to the footplate. Therefore, stable fixation of prostheses is desirable but has not been realized to date. In line with our experimental intention to realize a bony prosthesis fixation on the footplate, we designed a finite element model for the simulation of the interacting forces once an osseointegration was achieved. These preliminary results predict the mechanical feasibility of this endeavor and the necessary general preconditions, which have to be carefully considered. A specially designed titanium prosthesis anchor needs a minimal bony fixation of $104 \mu \mathrm{m}$ accretion height on the footplate to withstand all emerging forces. Therefore, providing a sort of artificial stapedial suprastructure in the form of a firm, preferably bony, integration of a prosthesis anchor on the footplate seems to be realistic and worthwhile from a mechanical and medical point of view.
\end{abstract}

Correspondence to: Marcus Neudert $\bullet$ Department of Medicine, Clinic of Otorhinolaryngology • TU Dresden • Fetscherstrasse 74, 01307, Dresden, Germany. Telephone: +49-351-4583107; fax: +49-3514584326; email: marcus.neudert@uniklinikum-dresden.de
Keyword: finite element model, stapes, footplate, tympanoplasty, middle ear prosthesis, osseointegration

\section{INTRODUCTION}

Aims and techniques of tympanoplasty

Tympanoplasty is well established for the reconstruction of the middle ear. The main issues of these techniques are closure of the tympanic membrane and reconstruction of the ossicular chain to preserve or restore the patient's hearing. Successful reconstruction of the more or less destroyed ossicles depends on biological, morphological, and prosthesis-related factors.

The restoration of a completely destroyed ossicular chain with only an intact stapes footplate remaining in the oval niche still represents one of the most sophisticated problems to be solved in otologic surgery. In the unfavorable event of a complete destruction of the stapedial arch, the interposition of a total ossicular replacement prosthesis (TORP), also known as columella prosthesis, is required. Presumably, the physiological vibration mode of the intact stapes footplate should be simulated by the prosthetic reconstruction to provide an optimal sound transmission to the inner ear. Consequently, the reconstruction technique and prostheses engineering should be based on the physiological vibration pattern of the ossicular chain.

Our knowledge of ossicular chain physiology has significantly increased over the past 15 years as a 
result of the enormous improvements in measurement technologies that have been made (Decraemer et al. 1991; Decraemer and Khanna 2000; Willi et al. 2002). The formerly established model of the ossicular chain moving as a rigid body with rotating movements of the malleus incus complex and piston-like movements of the stapes (Békésy 1936, 1941) was abandoned because of results of new noncontacting measurement techniques.

Thereafter, physiologic ossicular chain movements were discovered to be dependent on the frequency of transmitted sounds and reflect a wide range of motion patterns. The three-dimensional motion of the stapes footplate was extensively examined by different groups (Zahnert 2003; Hato et al. 2003; Decraemer and Khanna 2004). Measurements in temporal bone specimens with an intact ossicular chain, an intact cochlea, and normal air conduction stimulation showed predominantly piston-like motions at frequencies below $1 \mathrm{kHz}$. Above this frequency, the footplate motion becomes more complex with an increasing rotational aspect along both footplate axes and a maximum of this movement pattern at $6 \mathrm{kHz}$. There is recent data available that these tilting stapes movements elicit hearing (Eiber and Breuninger 2007; Sequeira et al. 2007). Although these findings need further investigation, prostheses optimization should address this aspect to achieve physiologic motion patterns in the future. As long as the columella is not stably fixed on the footplate, the rotational degrees of freedom are not coupled, and the generation of tilting motions is almost negligible.

\section{Concept of a bony fixed prosthesis anchor on the footplate}

The reconstruction of the stapes suprastructure seems to be a fascinating idea, both from the mechanical and the medical point of view. It might provide a more physiological movement pattern of the footplate, improving the mechanical aspects of sound transmission, and could offer a stable bony anchor for further prosthetic reconstruction. So far, the practical realization of the latter has failed. An intended and controlled bony fixation of any prosthesis material onto the footplate was not effective. Many attempts to establish such firm and long lasting contact of a TORP undersurface have been made, including footplate perforation to insert the prosthesis like a piston (Fisch and May 1994). On the other hand, aiming for a stable bony fixation of prostheses on the footplate is a conflicting purpose as it would audiologically and mechanically improve tympanoplasty but simultaneously raise the risk of adverse effects in revision surgery. In a recently published case report, an accidental stapes extraction in revision tympanoplasty was caused by an osseointegration of the TORP on the footplate (Sudhoff et al. 2005). This clearly reveals both the general potential of footplate osteoblasts to form new bone and the need of a compound prosthesis concept as soon as an osseointegration can be established. Therefore, we are embarking on the strategy of a bony fixed titanium anchor on the stapes footplate, hereafter called footplate anchor (FA), with a dismountable main prosthesis for coupling to the tympanic membrane (Fig. 1). This concept requires ossiculoplasty in two phases; whereas the FA is placed in the first step and the columella during a later surgical stage once the FA has been fixed to the stapes footplate by new tissue formation. First experimental data support the assumption that osteogenic substances, such as growth and differentiation factors, can induce a controlled osseointegration of titanium implants on the stapes footplate (Neudert et al. 2007). Thus, the finite element (FE) model presented here was designed to predict the extent of integration that is necessary to maintain a stable contact of the FA under conditions of hearing, manipulations occur-

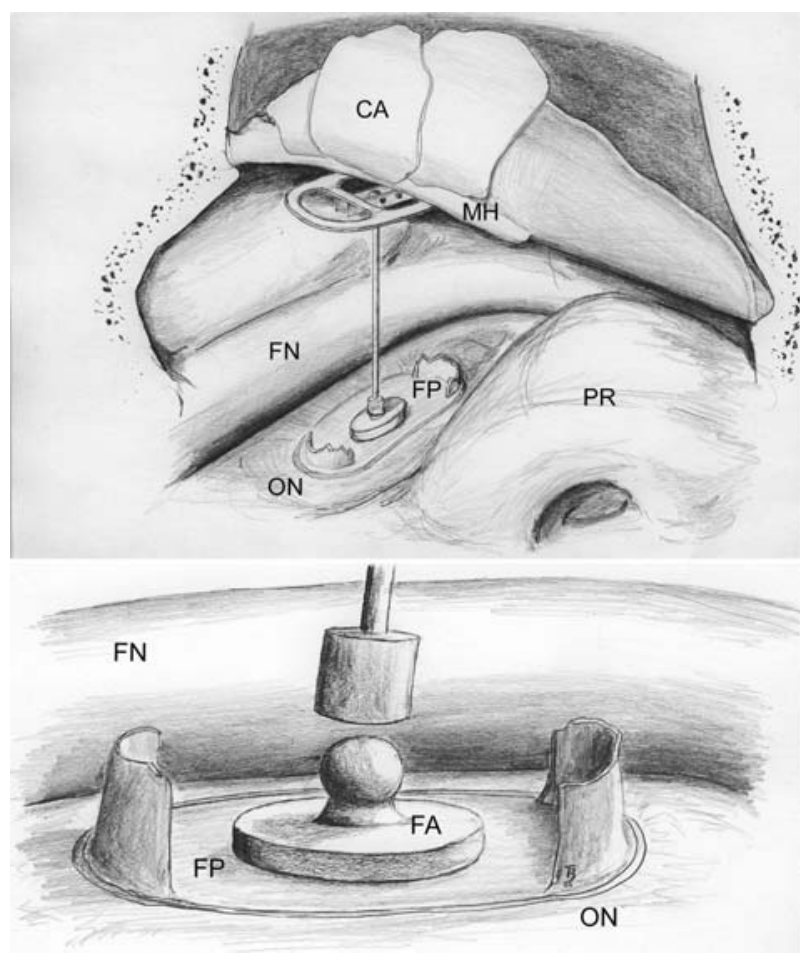

FIG. 1. Intraoperative situation: The stapes supra structure is destroyed and consecutively reconstructed with a compound prosthesis. The prosthesis head is placed beneath the malleus handle $(M H)$, and the eardrum is reconstructed with pieces of cartilage $(C A)$. In a first operation, the footplate anchor $(F A)$ was placed on the footplate $(F P)$ and consecutively integrated by newly formed tissue. Here, the main prosthesis is already mounted representing the second step after an interval to ensure a stable fixation of the FA. $O N$, oval niche, $P R$, promontory, and $F N$, facial nerve. 
ring in surgery and/or wound healing, and in quasi static pressure changes.

\section{MATERIALS AND METHODS}

\section{Definition of geometrical parameters and FE models}

The FA was designed as an oval stamp with three bumps at the lower surface to provide a sufficient and well-defined contact area to the individually shaped footplate with acceptable manufacturing costs. The three bumps act as starting zones for the integration. The strut of the FA, to which the main prosthesis will be coupled, is simplified as a bar for the simulations. FA geometry and its undersurface geometry are shown in Figure 2. Geometrical data of the stapes footplate were extracted from micro-CT scans of a temporal bone specimen and are consistent with the statistical dimensions of stapes measurements (Dass et al. 1966; Anson and Donaldson 1973). Data were imported to the finite element software using the IGES format (Initial Graphics Exchange Specification, ASME Y14.26M).

For prediction of the interacting forces occurring between the FA and the stapes footplate, a compound of the two single FE models was generated using a commercial finite element program (ANSYS, Inc.; Canonsburg, USA). The compound FE model and its dimensions are shown in Figure 3. Calculations of the stresses and strains occurring at the FA bone interface were obtained by applying different tissue qualities and quantities of fixation and specific material dependent failure criteria.

Assuming a directed tissue formation toward the positioned FA, diverse accretion patterns and quali-

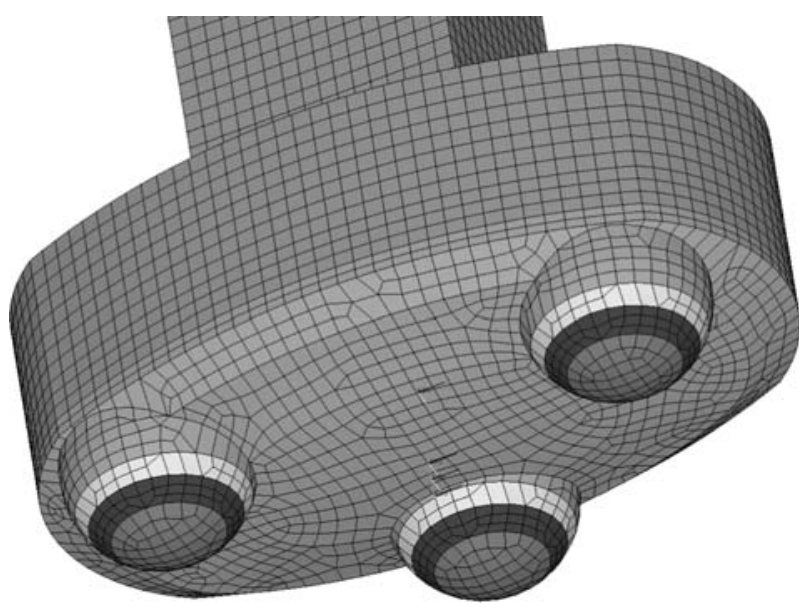

FIG. 2. View from below on the FE model of the prosthesis lower surface holding three hemispherical bumps. The gray scale values on the bumps indicate the three different heights of integration of the FA $(35,69$, and $104 \mu m)$.

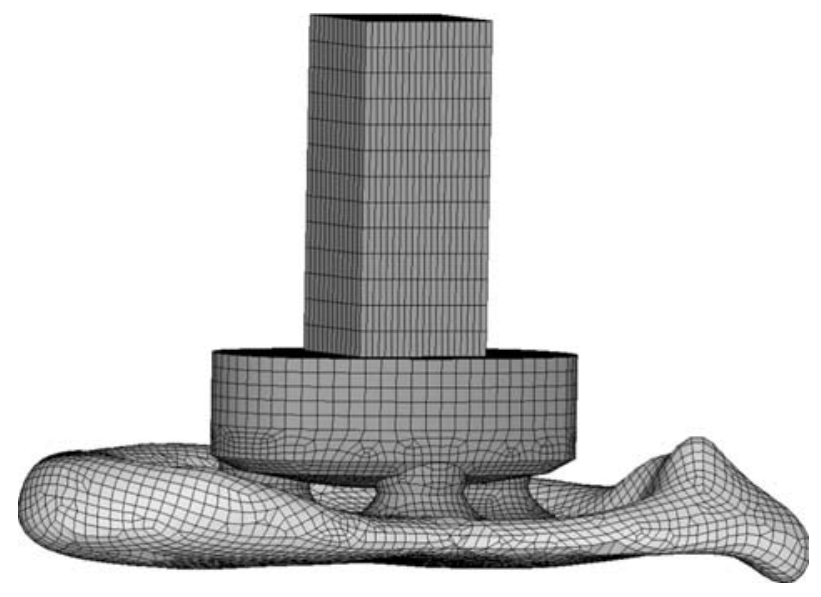

FIG. 3. FE model of the FA on the stapes footplate. The three bumps are partly embedded with newly formed tissue from the footplate surface, here up to a height of $104 \mu \mathrm{m}$ covering $60 \%$ of a bump surface.

ties are possible. Obviously, the biological process of forming new tissue and the subsequent integration of the FA will be a very inhomogeneous and individual process, but preliminary calculations necessitated simplification. An integration of only a single bump through all possible combinations of two or all three up to the whole FA is feasible. Moreover, based upon the histological footplate structure, the newly formed tissue potentially consists of the following: connective tissue, produced by fibroblasts localized in the middle ear mucosa, and bone, formed by osteoblasts of the underlying bony footplate region or chondrocytes of the cartilage layer that adjoins the vestibule. Accretion areas were presumed to be homogenous for all calculations. More precisely, they consist of only one specific tissue type within the single contact itself and among each other in multiple contact scenarios. Material properties used in the model are summarized in Table 1. Figure 4 shows the conceivable contact patterns out of three bumps (Fig. 4a-e); whereas three different heights of integration (e.g., 35,69 , and $104 \mu \mathrm{m}$, corresponding to 20,40 , and $60 \%$ of the whole bump surface) were considered plus a complete embedded FA (Fig. 4f). Resultant combinations were assessed under three default load cases.

\section{Loading of the FA}

The FA will basically be subjected to three types of loading during surgery and in the reconstructed middle ear: quasi static forces and moments when the main prosthesis is fitted, quasi static pressure changes in the middle ear (e.g., tympanometry), and dynamic forces associated with sound transmission. Load cases for the models were defined as worst case loads at the top of the FA strut. 
TABLE 1

Material parameters used for the model determined from Fung (1993) and Boyer et al. (1994) and own unpublished experiments

\begin{tabular}{lcc}
\hline Material & Young's modulus in $\mathrm{MPa}$ & Poisson's ratio \\
\hline Titanium & $1.02 \mathrm{e} 05$ & 0.34 \\
Bone & $2.0 \mathrm{e} 04$ & 0.45 \\
Cartilage & 2.0 & 0.45 \\
Elastin & 0.6 & 0.45 \\
\hline
\end{tabular}

Mounting and positioning of the main prosthesis on the FA will apply both forces and moments to the fixed FA on the footplate. On the basis of a direct mechanical manipulation on the strut, these forces must be considered as the highest to be tolerated. Investigations on other prostheses like the titanium clip prosthesis (Hüttenbrink et al. 2004b) or the articulated ball joint prosthesis (Beleites et al. 2004) showed maximum forces for installation and removal of at most $200 \mathrm{mN}$. Because of anatomical limitations, the angle at which the mounted prosthesis is finally placed is a maximum of $45^{\circ}$ out of the strut axis. An upright prosthesis mounting allows this angle to be reduced to $10^{\circ}$.

Manipulations on the plate of the main prosthesis will additionally produce a moment applied to the FA strut of about $0.035 \mathrm{mNm}$ (Beleites et al. 2004). This moment results from frictional forces within the joint between the two parts of the prosthesis construction. Quasi static pressure changes in the middle ear induce pressure changes of about $400 \mathrm{daPa}$ across the tympanic membrane (tympanometry). Taking the area of the tympanic membrane as $70 \mathrm{~mm}^{2}$ results in a force of approx. $280 \mathrm{mN}$. Usually, this force is partly borne by the elastic suspension of the (reconstructed) tympanic membrane resulting in effective load forces consistently less than $280 \mathrm{mN}$ at the footplate. This is supported by investigations on the titanium clip prosthesis (Hüttenbrink et al. 2004b) at which the prosthesis removal force of $200 \mathrm{mN}$ was never exceeded when applying forces equivalent to the mentioned pressure changes.

Furthermore, calculations with a finite element model of the middle ear (Bornitz et al. 1999) showed that about $50 \%$ of the static load of $400 \mathrm{daPa}$ is borne by the tympanic membrane. Thus, it appears that the resulting force transferred to the stapes head is even lower with approx. $100 \mathrm{mN}$ for a quasi static pressure change of $400 \mathrm{daPa}$. Hence, the most likely maximum force because of static pressure changes of around $100 \mathrm{mN}$. $200 \mathrm{mN}$ have to be considered as the worst case of maximum static forces acting on the FA at the stapes footplate. However, extreme pressure changes can never be excluded, and for this reason, the compound prosthesis possesses a self-loosening mechanism that is activated above $200 \mathrm{mN}$.

The loads are transferred to the integration zone of the FA footplate interface via the joint of the compound prosthesis. From an anatomical point of view, the maximum angle between the two parts of the compound prosthesis is about $45^{\circ}$, as the footplate is localized in the oval niche, and the plate of the main prosthesis has to be coupled to the tympanic membrane. This represents the worst case angle because forces acting perpendicular to the long axis of the FA will produce highest loading on the accretion zone (lever mechanism).

Dynamic forces associated with sound transmission are calculated for the upper hearing limit of $120 \mathrm{~dB}$ sound pressure level (SPL). Assuming a complete pressure absorption by the tympanic membrane, a maximum resulting force of about $1.4 \mathrm{mN}\left(20 \mathrm{~Pa} \cdot 70 \mathrm{~mm}^{2}\right)$ will be transferred to the reconstructed ossicular chain
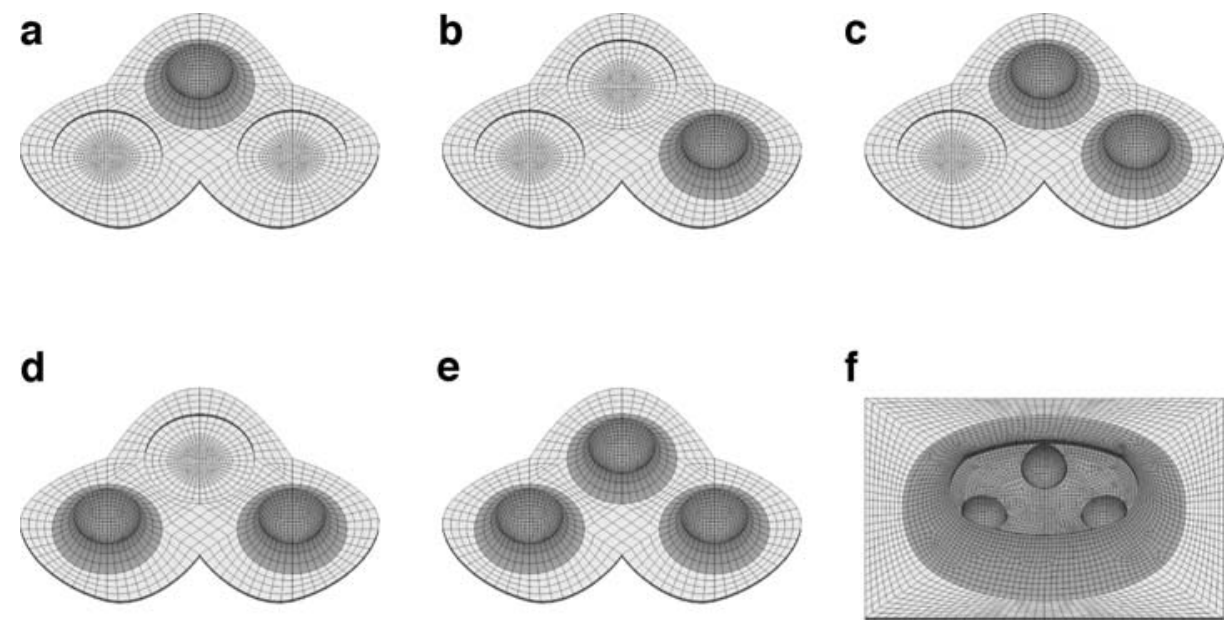

FIG. 4. Possible combinations of the bump accretion patterns. $\mathbf{a}, \mathbf{b}$ One single; $\mathbf{c}, \mathbf{d}$ two or $\mathbf{e}$ all three bumps and the complete embedding of the $\mathbf{f}$ whole FA basis. The shown accretion height is $104 \mu \mathrm{m}(60 \%$ of the bump surface) for $\mathbf{a}-\mathbf{e}$ and $260 \mu \mathrm{m}$ for $\mathbf{f}$. 
and thus to the FA. Extreme impulse noises of $150 \mathrm{~dB}$ SPL (e.g. firecrackers, firearms) were also considered in the calculations. The load angle of $45^{\circ}$ is the same as for the forces because of static pressure changes. The loading conditions are summarized in Table 2.

\section{Failure criteria for the accretion zone}

Compared to all involved elements and their connections in a reconstructed middle ear (tympanic membrane, titanium compound prosthesis, and stapedial footplate), the accretion area in the FA footplate interface must be considered as the potentially weakest part. Thus, all exerted stresses or strains will primarily act upon that region, leading to a dislocation from the FA from the footplate once the tissuespecific loading capacity is exceeded.

From the audiological and mechanical point of view, a formation of new bone in the accretion area represents the ideal situation. Because the proliferation of other tissue entities that are present in the footplate region (connective tissue, cartilage) is within the realm of possibility, their specific maximum loading capacity must also be taken into account. These so-called failure criteria are taken from literature and are summarized in Table 3. Bone as a hard material is more sensitive to stress; whereas cartilage and connective tissue as soft materials are more sensitive to strain. The failure criterion for bone is therefore defined as $125 \mathrm{MPa}$ of stress (Fung 1993).

The values for cartilage and connective tissue cover a wide range and depend very much on the special material composition. The situation most comparable to our investigations is the fracture healing by Andreassen et al. (2004). Thus, an ultimate strain of $1.0 \Delta l / l$ (i.e., $100 \%$ ) will be used as failure criterion for cartilage and connective tissue. The values for ultimate stress and strain were obtained for uniaxial load; whereas within the osseoin-

\begin{tabular}{|c|c|c|}
\hline \multicolumn{3}{|c|}{ TABLE 2} \\
\hline \multicolumn{3}{|c|}{ Loading conditions of the footplate anchor } \\
\hline Condition & Load & $\begin{array}{l}\text { Load angle } \\
\text { from upright } \\
\text { prosthesis axis }\end{array}$ \\
\hline $\begin{array}{l}\text { Dynamic force, } \\
\text { sound transfer } 120 \mathrm{~dB}\end{array}$ & $1.4 m N$ & $45^{\circ}$ \\
\hline Impulse noise $150 \mathrm{~dB}$ & $44.2 \mathrm{mN}$ & $45^{\circ}$ \\
\hline $\begin{array}{l}\text { Quasi-static pressure changes } \\
\text { (e.g., tympanometry) }\end{array}$ & $200 m N$ & $45^{\circ}$ \\
\hline With load bearing of t.m. & $100 \mathrm{mN}$ & $45^{\circ}$ \\
\hline Mounting of main prosthesis & $200 m N$ & $10^{\circ}$ \\
\hline Positioning of main prosthesis & $0.035 \mathrm{mNm}$ & $x$ - and $y$-axis \\
\hline
\end{tabular}

Coordinate system: $z$-axis is the upright prosthesis axis; $x$ and $y$ are the short and long axis in the footplate plane; t.m. tympanic membrane tegration zone, there will be a multiaxial stress strain state. For bone, Fung (1993) suggested the von Mises criterion to compare the multiaxial state of stress and strain with the ultimate values from uniaxial experiments. This criterion was also used for the other materials.

\section{Structural analyses}

The structural static analyses of the FE models were carried out under the assumptions of linear elastic material behavior and geometric linearity. A tentative nonlinear static analysis, including geometric and material nonlinearities (see Appendix), provided results with about $50 \%$ maximum deviation to the linear analysis (for strains up to 1 ). This deviation is in the same order of magnitude as the uncertainties in the material parameters and failure criteria for cartilage and soft tissue. Therefore, nonlinear effects were neglected for reasons of calculation efficiency. Furthermore, strains are always lower when the nonlinear material law is used (nonlinear analysis). Thus, results from a linear analysis showing that a certain accretion type will bear the applied load are reliable. In contrast, predicted failure of a certain contact pattern has higher uncertainty.

The contact at surfaces between the FA and the footplate is assumed to be ideal (rigid coupling). The element type used to mesh the geometrical models, prosthesis and stapes, is ANSYS element SOLID186. SOLID186 is a higher order three-dimensional 20node structural solid element with quadratic displacement behavior and $3 d f$ per node (translations in nodal $\mathrm{x}, \mathrm{y}$, and $\mathrm{z}$ directions). ANSYS element MPC184 is used at the point of load application to ensure realistic force transmission. MPC184 is a two-node multipoint constraint rigid beam element with $6 d f$ per node. For interpretation of the accretion zone effects, von Mises equivalent stresses and strains were computed and compared with respective criteria.

\section{RESULTS}

Maximum tolerated loads of the FA footplate interface are dependent on the tissue consistency in the accretion zone, the extent of integration of the FA, and the angle of the acting force, additionally producing a moment upon the lever mechanism.

The maintenance of solid tissue connections, like bone, is limited by applied stresses; whereas failure of flexible tissues (e.g., cartilage, connective tissue) primarily occurs when applied strains are exceeding the limit. Therefore, the presentation of the computed data is limited to the assignable cause of failure, although both conditions were calculated in the model. 
TABLE 3

Failure criteria for bone, connective tissue, and cartilage

\begin{tabular}{|c|c|c|c|c|}
\hline Material & & $\begin{array}{l}\text { Ultimate } \\
\text { tensile strength } \\
\text { (stress) in MPa }\end{array}$ & $\begin{array}{l}\text { Ultimate } \\
\text { elongation } \\
\text { (strain) } \Delta l / l\end{array}$ & Reference \\
\hline Bone & Wet, compact & 125 & 0.014 & Fung (1993) \\
\hline \multirow[t]{3}{*}{ Cartilage } & $\begin{array}{l}\text { Articular cartilage, bovine humeral } \\
\text { joints, middle region }\end{array}$ & 16 & $0.8 \ldots 1.2$ & Woo et al. (1976) \\
\hline & $\begin{array}{l}\text { Human menisci, central } \\
\text { middle, radial }\end{array}$ & 3.6 & 0.58 & Tissakht and Ahmed (1995) \\
\hline & Circumferential & 12.5 & 0.24 & \\
\hline \multirow[t]{3}{*}{ Connective tissue } & Skin of Xenopus laevis (male) & 15 & 0.6 & Greven et al. (1995) \\
\hline & Female & 11 & 1.1 & \\
\hline & Callus material (fracture zone of rat tibia) & 33 & 1 & Andreassen et al. (2004) \\
\hline
\end{tabular}

Mounting and positioning of main prosthesis

Mounting of the main prosthesis will produce the highest loading of the integrated FA. A force of about $200 \mathrm{mN}$ will be transferred to the accretion zone in direct extension of the FA strut, at most. From the anatomical point of view, a deviation of approx. $10^{\circ}$ during prosthesis insertion is assumable. The resulting maximum stresses on the accretion zone under the mentioned conditions are shown in Table 4 . According to the used failure criteria (Table 3), the FA will be disrupted in the case of a bony fixation if only one bump is embedded up to a height of $35 \mu \mathrm{m}$. Any bony integration higher than $69 \mu \mathrm{m}$ at a single bump or a double contact on two bumps with $35 \mu \mathrm{m}$ will withstand the mounting stress. A homogeneous formation of cartilage in the accretion zone needs at least a $60 \%(104 \mu \mathrm{m})$ integration of all three bumps to endure the prosthesis mounting. In the case of a homogeneous connective tissue formation, the interface will be the weakest and even a complete embedding does not withstand the occurring strains. Maximum stresses and strains always occurred at the bottom of the hemispherical bumps as shown in Figure 5.

Once the main prosthesis is mounted on the FA, it has to be adjusted to the individual anatomical situation to achieve an ideal position for sound transmission. Moments thus generated in the accretion zone are summarized in Table 4 . For certain contact conditions (like triple contact), applied moments on the long axis of the footplate (y-axis) induce higher stresses and strains than moments about the x-axis. In x-axis, a moment of $35 \mathrm{mNm}$ is tolerated in case of any bony fixation down to a $20 \%$ $(35 \mu \mathrm{m})$ contact of a single bump. Cartilage integration requires at least a $40 \%(69 \mu \mathrm{m})$ adherence to all three bumps to safely persist and a complete fixation of the FA $(260 \mu \mathrm{m})$ is necessary if the accretion area consists of connective tissue. In the direction of the long axis (y-axis), no changes in stability are observed for bony contacts. Newly formed cartilage could sustain the loading if at least two $20 \%$ contacts
$(35 \mu \mathrm{m})$ in the $\mathrm{y}$-axis direction were formed. Similar conditions are needed in the case of connective tissue proliferation, however up to an integration of $40 \%(69 \mu \mathrm{m})$. If three contacts are established, the integration height has to reach $40 \%(69 \mu \mathrm{m})$, as an integration of only $20 \%(35 \mu \mathrm{m})$ of each bump would not endure the loading.

\section{Quasi static pressure changes}

Quasi static pressure changes occurring during altitude changes will provoke forces similar to the mounting of the main prosthesis. However, after positioning of the prosthesis plate under the tympanic membrane or the malleus handle, the angle between the prosthesis and the FA strut can be as much as $45^{\circ}$. This indeed represents the worst case in terms of loading the accretion zone and challenges its stability the most. As described in Table 4, in the case of bone formation, one $60 \%$ embedded bump or two $40 \%$ integrated bumps are necessary to ensure a stable merge between the FA and the stapes footplate. Even a complete integration of the FA with cartilage or connective tissue would result in its luxation from the footplate. As the occurring static pressures are partly borne by the tympanic membrane, the resulting force could favorably be reduced to $100 \mathrm{mN}$ at a $45^{\circ}$ angle. If so, any bony integration of a single bump of at least $40 \%(69 \mu \mathrm{m})$ will withstand the arising stress. A double contact of $35 \mu \mathrm{m}(20 \%)$ integration height will withstand the stress if they are oriented in the long axis (y-axis), whereas $40 \%$ of two bumps have to be embedded in the case of an orientation in the short axis (x-axis). However, even a completely integrated FA undersurface $(260 \mu \mathrm{m})$ will not endure the loading that occurs in the case of new formation of cartilage or connective tissue, respectively.

\section{Dynamic forces (sound transmission)}

During sound transmission, the accretion zone is exposed to a force of about $1.4 \mathrm{mN}$ at a maximum 
TABLE 4

Maximum loading (stress, strain) in the accretion zone for different loads and three types of tissue (bone, cartilage-like, connective tissue)

\begin{tabular}{|c|c|c|c|c|c|c|c|c|c|}
\hline \multirow[t]{3}{*}{ Load case } & \multicolumn{9}{|c|}{ Minimal type of contact without failure } \\
\hline & \multicolumn{3}{|c|}{ Bone } & \multicolumn{3}{|c|}{ Cartilage } & \multicolumn{3}{|c|}{ Connective tissue } \\
\hline & $\begin{array}{l}\text { Type of } \\
\text { contact }\end{array}$ & $\begin{array}{c}\text { Accretion } \\
\text { height }(\mu \mathrm{m})\end{array}$ & $\begin{array}{c}\text { Max. } \\
\text { stress (MPa) }\end{array}$ & $\begin{array}{l}\text { Type of } \\
\text { contact }\end{array}$ & $\begin{array}{c}\text { Accretion } \\
\text { height }(\mu \mathrm{m})\end{array}$ & $\begin{array}{l}\text { Max. } \\
\text { strain }\end{array}$ & $\begin{array}{l}\text { Type of } \\
\text { contact }\end{array}$ & $\begin{array}{c}\text { Accretion } \\
\text { height }(\mu \mathrm{m})\end{array}$ & $\begin{array}{l}\text { Max. } \\
\text { strain }\end{array}$ \\
\hline \multirow[t]{4}{*}{ Force of $200 \mathrm{mN}$ at $10^{\circ}$} & 0 & 69 & 65.2 & \multirow[t]{4}{*}{$\because$} & \multirow[t]{4}{*}{104} & \multirow[t]{4}{*}{0.96} & \multirow[t]{4}{*}{9} & \multirow[t]{4}{*}{260} & \multirow[t]{4}{*}{$(1.24)$} \\
\hline & 0 & 69 & 81.0 & & & & & & \\
\hline & $\bullet$ & 35 & 93.6 & & & & & & \\
\hline & $\therefore$ & 35 & 19.9 & & & & & & \\
\hline \multirow[t]{5}{*}{ Force of $200 \mathrm{mN}$ at $45^{\circ}$} & $\bullet$ & 104 & 99.4 & \multirow[t]{5}{*}{$\odot$} & \multirow[t]{5}{*}{260} & \multirow[t]{5}{*}{ (1.08) } & \multirow[t]{5}{*}{$\ominus$} & \multirow[t]{5}{*}{260} & \multirow[t]{5}{*}{$(4.14)$} \\
\hline & 0 & 104 & 107.8 & & & & & & \\
\hline & $\bullet$ & 69 & 93.2 & & & & & & \\
\hline & $\therefore$ & 69 & 72.8 & & & & & & \\
\hline & $\therefore$ & 35 & 46.8 & & & & & & \\
\hline \multirow[t]{4}{*}{ Force of $100 \mathrm{mN}$ at $45^{\circ}$} & 0 & 69 & 91.6 & \multirow[t]{4}{*}{9} & \multirow[t]{4}{*}{260} & \multirow[t]{4}{*}{0.54} & \multirow[t]{4}{*}{$\odot$} & \multirow[t]{4}{*}{260} & \multirow[t]{4}{*}{$(2.07)$} \\
\hline & 0 & 69 & 100 & & & & & & \\
\hline & $\bullet$ & 69 & 46.6 & & & & & & \\
\hline & $\therefore$ & 35 & 105 & & & & & & \\
\hline \multirow{2}{*}{$\begin{array}{l}\text { Moment of } 0.035 \mathrm{mNm} \\
\text { around the } \mathrm{x} \text {-axis }\end{array}$} & $\bullet$ & 35 & 58.5 & \multirow[t]{2}{*}{$\because$} & \multirow[t]{2}{*}{69} & \multirow[t]{2}{*}{0.6} & 9 & 260 & 0.67 \\
\hline & 0 & 35 & 58.5 & & & & & & \\
\hline Moment of $0.035 \mathrm{mNm}$ & 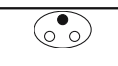 & 35 & 58.5 & $\bullet$ & 35 & (1.43) & $\bullet$ & 104 & $(4.76)$ \\
\hline around the $y$-axis & 0 & 35 & 59.2 & $\because$ & 104 & 0.5 & $\therefore$ & 69 & 0.92 \\
\hline & & & & & & & $\therefore$ & 69 & 0.92 \\
\hline Force of $1.4 \mathrm{mN}$ at $45^{\circ}$ & 0 & 35 & 3.85 & 6 & 69 & 0.39 & 0 & 104 & 0.81 \\
\hline (120 dB SPL) & 0 & 35 & 4.14 & 0 & 69 & 0.42 & $\circ$ & 104 & 0.89 \\
\hline & & & & $\bullet$ & 35 & 0.58 & $\bullet$ & 69 & 0.65 \\
\hline & & & & $\therefore$ & 35 & 0.43 & $\therefore$ & 69 & 0.49 \\
\hline & & & & & & & $\therefore$ & 35 & 0.17 \\
\hline Force of $44.2 \mathrm{mN}$ at $45^{\circ}$ & 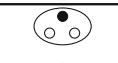 & 35 & 121.7 & $\therefore$ & 69 & 0.95 & 9 & 260 & 0.95 \\
\hline$(150 \mathrm{~dB}$ SPL $)$ & 0 & 35 & (130.8) & & & & & & \\
\hline Material ultimate values & & & $125 \mathrm{MPa}$ & & & 1.0 & & & 1.0 \\
\hline
\end{tabular}

The minimal type of contact that could bear the load without failure is stated. Less contact points or less contact height result in stress and strain, which exceed the material ultimate values. Values in brackets indicate already failed configuration types.

angle of $45^{\circ}$ to the FA strut. As shown in Table 4 , the resultant loading is negligible for a bony integrated FA to whatever degree. The failure criterion of cartilage will be exceeded, causing a dislocation of the FA from the footplate if a single bump is embedded just to $20 \%$ of its surface $(35 \mu \mathrm{m})$. An accretion height of $104 \mu \mathrm{m}(60 \%)$ for a sole embed- ded bump or at least $69 \mu m(40 \%)$ for a double contact are necessary to sustain the arising loading in the case of a connective tissue contact. Any triple contact down to $20 \%$ of the bump surface is able to cope with the loading during sound transmission.

A bony integrated FA will also withstand impulse noises (up to $150 \mathrm{~dB}$ ) for any type of contact and 


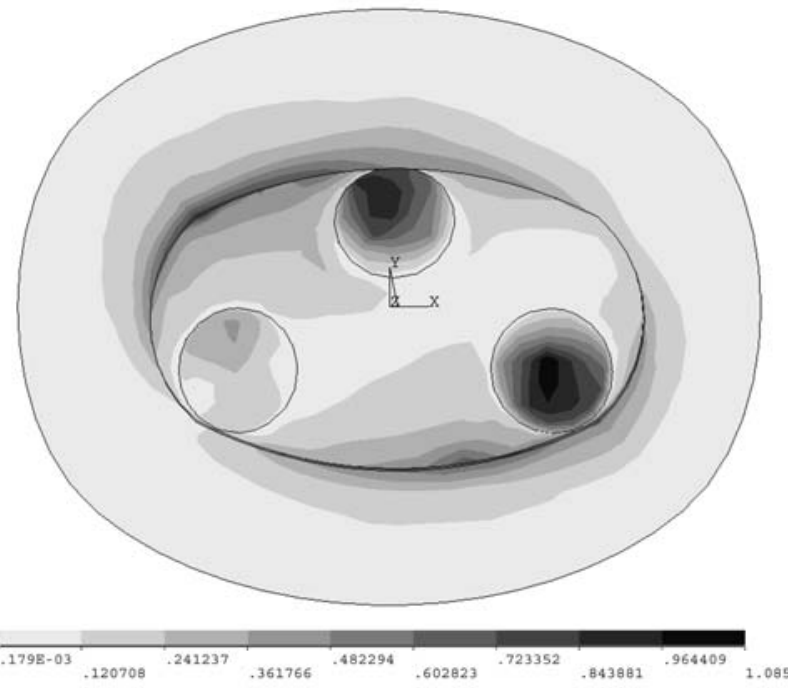

FIG. 5. Equivalent strain (von Mises) in the accretion zone for quasi-static pressure changes with maximum values (dark) at the bottom of the hemispherical bumps. The accretion zone for this case is made up of cartilage, and the FA is completely embedded.

accretion height, accept one single contact at $35 \mu \mathrm{m}$ $(20 \%)$. In the case of cartilage and tissue accretion types, a triple contact with $69 \mu \mathrm{m}$ accretion height or complete contact is necessary, respectively.

\section{DISCUSSION}

Stable and safe coupling between prostheses and the remaining ossicular rudiments are the preconditions for satisfactory hearing results in otosurgery (Eiber et al. 2000). Dislocation of the prosthesis and/or interposition of connective tissue impeding a direct prosthesis bone contact are important reasons for poor postoperative sound transmission (Katzke et al. 1982; Smyth 1983; Hüttenbrink 1994). Because of the small and special anatomical situation in the middle ear, the anchorage of ossicular prostheses is reliant on clamp and/or clip mechanisms, which are not applicable on a solitary remaining footplate (Helms 1996). The intraoperative adjustment of the columella strut on the footplate with pieces of connective tissue or cartilage (Jahnke 1987; Plester et al. 1989; Fisch and May 1994) and/or its dynamic bracing between the footplate and the tympanic membrane by a long TORP assembly represent the current clinical practice. However, an apparently reliably positioned TORP prosthesis on the stapes footplate imminently runs the risk of dislocation at the end of surgery. Numerous forces caused by changes in atmospheric pressure, middle ear effusion, or scar tissue development in wound healing can sooner or later destroy the main prosthesis fit on the footplate. Besides other medical factors, prosthesis dislocation is accountable for 25-45\% of unsatisfactory postoperative hearing results (Katzke et al. 1982). In addition, any interposition of elastic components in the prosthesis footplate interface drastically decreases an effective sound transmission. For both of these reasons, a stable bony fixation on the footplate would be preferable. Moreover, tympanic membrane reconstruction with cartilage or fascia is easier when the prosthesis plate presents a stable tray for bearing the reconstruction, especially in canal wall down surgery.

The use of a cartilage guide, placed in the oval niche on top of the footplate, seems to represent the best available device at present (Hüttenbrink et al. 2004a). Although it provides a safe and stable guidance for the columella prosthesis on the footplate surface, it still does not prevent the potential interposition of connective tissue. The cartilage guide does indeed decrease the postoperative air conducted hearing loss by about $5.6 \mathrm{~dB}$ (mean) but does not avoid a TORP uplift as the prosthesis itself is not stably fixed on the footplate. Thus, the cartilage guide is an excellent device to avoid a prosthesis shift within the footplate center, which represents the optimal site for sound transfer (Asai et al. 1999); however, a stable contact in perpendicular direction (prosthesis uplift and dislocation) is not secured.

On the other hand, a durably anchored prosthesis on the stapes footplate also evokes potential risks. Inner ear integrity equivalent to the patient's hearing must be ensured at all times. For the firm and stable connection of a prosthesis on top of the footplate, a compound prosthesis containing a demounting device with a self-loosening mechanism is mandatory. As mentioned, an accidental stapes extraction was reported to be caused by a bony fixed titanium TORP on the footplate (Sudhoff et al. 2005).

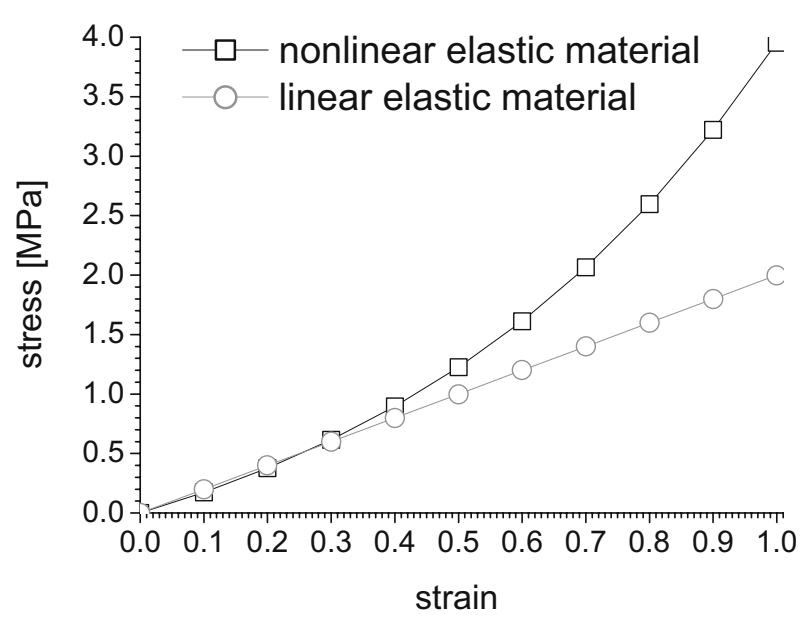

FIG. 6. Linear vs nonlinear elastic material law for cartilage used for the calculations. 
Temporal bone measurements have yielded a force of approximately $1,000 \mathrm{mN}$ to exceed the strength of the annular ligament and lead to a stapes luxation (Hüttenbrink et al. 2004b). Therefore, the dismountable coupler device of the prosthesis concept requires a self-loosening mechanism, which is activated at forces significantly lower than $1,000 \mathrm{mN}$. The described FA will be coupled to the main prosthesis by an established mechanism (not shown) that provides both the stability necessary to bear the physiological demands and the self-loosening safety aspect that avoids crucial footplate and/or annular ligament damage.

The strategy of a compound prostheses concept is thereby restricted to the following preconditions: the fundamental ability to induce a tissue formation on the footplate and the mechanical stability of the footplate anchor once integration was successful.

As a consequence of the different tissue entities present in the stapes footplate, the integration of the FA could be mediated by fibroblasts of the mucosal surface, osteoblasts of the underlying bone layer, or chondrocytes of the cartilage layer adjoining the vestibule. Depending on the histological tissue quality and the height of integration in the accretion zone of the FA footplate interface, varying loads can be tolerated. The tissue-specific failure criteria reflect the requirement of a preferably bony fixation. For cartilage and connective tissue, the maximum tolerated strain $(1.0 \Delta l / l$, corresponding to $100 \%$ elongation; Woo et al. 1976; Tissakht and Ahmed 1995; Greven et al. 1995; Andreassen et al. 2004) will be exceeded even for a completely embedded FA under an applied force of $200 \mathrm{mN}$ at $45^{\circ}$. These quasi static pressure changes occur during altitude changes or tympanometry and represent the maximum loading of the accretion zone. For this load, at least a single FA bump has to be bony embedded up to $104 \mu \mathrm{m}$ $(60 \%)$ or two bumps to a height of $69 \mu \mathrm{m}(40 \%)$ to securely pass the emerging stress as it will fail at 125 MPa (Fung 1993). Assuming a load reduction down to $100 \mathrm{mN}$ as a result of the other load bearing structures (especially tympanic membrane), a complete embedding $(260 \mu \mathrm{m})$ of the FA with connective tissue still fails, whereas a cartilage embedding $(260 \mu \mathrm{m})$ is able to endure (Table 4).

As mounting of the main prosthesis on top of the FA strut will be achievable at an angle of $10^{\circ}$ from the axis, the employed force of $200 \mathrm{mN}$ will not load the accretion zone to the same extent as at $45^{\circ}$ (quasi static pressure).

Given the quasi static pressure with $100 \mathrm{mN}$ at $45^{\circ}$ as the worst case scenario, a formation of cartilage or connective tissue in the accretion zone is not sufficient for a stable integration of the FA. Hence, all other constellations of minor loadings in the accretion zone are irrelevant because sound transmission is only possible once a main prosthesis was successfully mounted and positioned. Sound transmission therefore presumes the persistence of the FA footplate contact during the process of erection.

The new tissue formation in the accretion zone was postulated to be homogenous and isotropic in this FE model, which assumably is not the case in vivo. In fact, a heterogeneous tissue development with different amounts of bone, cartilage, and connective tissue is much more realistic. Nonetheless, a limitation to three separate tissue entities in this FE model was necessary because sufficient histological data on the consistency are pending and would extremely complicate the already sophisticated model. Individual variations will also be unpredictable and it would not allow for general statements. The stability of an actual accretion zone and its ability to cope with the applied loading can be anticipated to lie within the limits of the three separate tissue entities. However, the results clearly indicate the preferable bony fixation to provide a stable fixation of the FA onto the stapes footplate.

The FA geometry was designed to provide a sufficient and well-defined contact area to the individually shaped footplate with acceptable manufacturing costs. The tripod shape of the hemispherical bumps on the undersurface leads to differences in the maximum tolerated loads depending on the opted fixation pattern. However, this is only reflected in the calculated values. It did not affect the general stability of an integration pattern at any time (Table 4). Therefore, the geometrical shape of the undersurface is more important for the integration process itself than for its stability once an embedding is established.

The attempt to develop an artificial stapedial suprastructure by inducing a firm integration of a prosthesis anchor on the footplate seems to be realistic from the biomechanical point of view. To endure all arising forces in the accretion zone, a minimal bony fixation at a height of $104 \mu \mathrm{m}(60 \%)$ for one bump or of $69 \mu \mathrm{m}$ (40\%) for two bumps is necessary. The sole, even complete, embedding with connective tissue or cartilage is not appropriate to assure a stable and firm integration.

First results from animal experiments show that the osseointegration of titanium implants on the stapes footplate can be realized. Osteogenic growth factors are able to induce the formation of new bone on the footplate surface and thereby affix an anchor for subsequent ossicular reconstruction. Thus, in the near future, further results from in vivo experiments will allow the evaluation of the histological characterization of the accretion zone consistency. 


\section{ACKNOWLEDGEMENTS}

The authors would like to thank PD Dr. Ing. habil. Dieter Scharnweber for providing the micro-CT scans and Toni Sander for supplying linguistic support.

This work was supported by a grant from the Bundesministerium für Bildung und Forschung (03I4034A).

The authors certify that they have not entered into any agreement that could interfere with their access to the data on the research nor upon their ability to analyze the data independently, to prepare manuscripts, and to publish them.

\section{APPENDIX}

\section{Linear vs nonlinear static analysis}

Linear and nonlinear static analysis were compared for the case of cartilage in the accretion zone and complete contact. The Young's modulus for linear elastic cartilage was determined from tension experiments with strains of up to 0.3 . Elastic cartilage from the concha was used for these experiments as this cartilage exhibits a spatial homogeneous elastin fiber network. The nonlinear elastic material law was chosen to fit the linear material up to $30 \%$ of strain and to follow an exponential law according to (Woo et al. 1976):

$$
\sigma=1 e^{1.6 \varepsilon-1} .
$$

This material law represents the stress stiffening of cartilage because of the stretching of the elastin network (exponentially increasing stiffness, see Fig. 6). A quasi static load of $200 \mathrm{mN}$ at an angle of $45^{\circ}$ was applied. This gave strains up to 1.08 (engineering strain) in the linear analysis, corresponding to a Hencky strain of 0.73 (also called logarithmic or true strain). The maximum Hencky strain from the nonlinear analysis was 0.34 . There is a maximum of $54 \%$ deviation between the linear and nonlinear analysis. This deviation is less for lower strains. Both analyses provide about the same results for strains up to 0.4 (engineering strain).

Strains are usually provided as engineering strains $\epsilon=\Delta l / l$ (elongation divided by initial length), which was also used throughout this manuscript. With nonlinear analysis and large strains in contrast, the logarithmic or Hencky strain, $e$ is calculated. It is connected to the engineering strain by: $e=\ln (1+\epsilon)$.

\section{REFERENCES}

Andreassen TT, Willick GE, Morley P, Whitfield JF. Treatment with parathyroid hormone hPTH(1-34), hPTH(1-31), and monocyclic hPTH(1-31) enhances fracture strength and callus amount after withdrawal fracture strength and callus mechanical quality continue to increase. Calcif. Tissue. Int. 74(4):351-356, 2004.

Anson BJ, Donaldson JA. Surgical Anatomy of the Temporal Bone and Ear. Philadelphia, Saunders, 1973.

Asai M, Huber A, Goode R. Analysis of the best site on the stapes footplate for ossicular chain reconstruction. Acta. Otolaryngol. 119:356-361, 1999.
BÉKÉSY Gv. Zur Physik des Mittelohres und über das Hören bei fehlerhaftem Trommelfell. Akust. Zeits. 1:13-23, 1936.

BéKÉsY Gv. Über die Messung der Schwingungsamplitude der Gehörknochelchenmittels einer kapazitiven Sonde. Akust. Zeits. 6:1-16, 1941.

Beleites T, Zahnert T, Bornitz M, Hofmann G, Hüttenbrink K. Die Gelenkprothese-Eine weitere Optimierung des Prothesendesigns beim Gehörknöchelchenersatz. Laryngorhinootologie 83(2):11/4, 2004.

Bornitz M, ZahNert T, HaRdTKe HJ, HütTENBrink KB. Identification of parameters for the middle ear model. Audiol. Neuro-otol. 4(3-4):163-169, 1999.

Boyer R, Welsch G, Collings EW. Materials Properties Handbook: Titanium Alloys. Materials Park, OH, ASM International, 1994.

Dass R, Grewal BS, Thapar SP. Human stapes and its variations. I. General Features. J. Laryng. Otol. 80:11-25, 1966.

Decraemer W, Khanna S. New insights into vibration of the middle ear. In: Rosowski JJ, Merchant SN (eds) Second International Symposium on Middle-Ear Mechanics in Research and Otosurgery, Boston, MA, USA, 1999. The Hague, The Netherlands, Kugler, pp. 23-38, 2000.

Decraemer WF, Khanna SM. Measurement, visualization and quantitative analysis of complete three-dimensional kinematical data sets of human and cat middle ear. In: Gyo K, Wada H, Hato N, Koike T (eds) Middle Ear Mechanics in Research and Otology. Singapore, World Scientific, pp. 3-10, 2004.

Decraemer WF, Khanna SM, Funnell WR. Malleus vibration mode changes with frequency. Hear. Res. 54:305-318, 1991.

Eiber A, Breuninger C. Mechanical excitation of complex stapes motion in guinea pigs. In: Huber A, Eiber A (eds.) Middle Ear Mechanics in Research and Otology. Singapore, World Scientific, pp. 132-138, 2007.

Eiber A, Freitag HG, Schimanski G, Zenner HP. On the coupling of prostheses to the middle ear structure and its influence on sound transfer. In: Rosowski JJ, Merchant SN (eds.) Second International Symposium on Middle-Ear Mechanics in Research and Otosurgery, Boston, MA, USA, 1999. The Hague, The Netherlands, Kugler, pp. 297-308, 2000.

Fisch U, MAY J. Tympanoplasty, mastoidectomy and stapes surgery. Struttgart, NY, Georg Thieme, 1994.

FUNG YC. Biomechanics: mechanical properties of living tissues (2nd Ed.). Springer, Berlin Heidelberg New York, 1993.

Greven H, Zanger K, Schwinger G. Mechanical properties of the skin of Xenopus laevis (Anura, Amphibia). J Morphol 224(1):1522, 1995.

Hato N, Stenfelt S, Goode RL. Three-dimensional stapes footplate motion in human temporal bones. Audiol. Neurootol. 8(3):140-152, 2003.

Helms J. Kopf- und Halschirurgie, Thieme, Stuttgart, volume 2, chapter Sanierende und rekonstruktive Operationen an Gehörgang, Mittelohr und Felsenbein., pp. 67-129, 1996.

HütTENBRINK KB. Die operative Behandlung der chronischen Otitis media. I-III. HNO 42:582-593, 648-657, 701-718, 1994.

Hüttenbrink KB, Zahnert T, Beutner D, Hofmann G. The cartilage guide: a solution for anchoring a columella-prosthesis on footplate. Laryngorhinootologie 83(7):450-456, 2004a.

Hüttenbrink KB, Zahnert T, Wüstenberg EG, Hofmann G. Titanium clip prosthesis. Otol. Neurotol. 25(4):436-442, 2004b.

JAHNKE K. Fortschritte in der Mikrochirurgie des Mittelohres. HNO 35:1-13, 1987.

Katzke D, Steinbach E, Schödermaier C. Zur Ursache derWiederentfernung allogener Anstoßtransplantate. Arch. Otorhinolaryngol. 235:525-528, 1982.

Neudert M, Ney M, Beleites T, Kluge A, Zahnert T. Osseointegration oberflächenbeschichteter Titanimplantate auf der Steigbügelfußplatte im Großtiermodell. In: 78. Jahresversammlung der Deutschen Gesellschaft für Hals-Nasen-Ohren- Heilkunde, 
Kopf- und Hals-Chirurgie e.V. Düsseldorf, German Medical Science (GMS), p. 25, 2007.

Plester D, Hildmann H, Steinbach E. Atlas der Ohrchirurgie. The Netherlands, Kohlhammer Verlag, 1989.

Sequeira D, Breuninger C, Huber A, Eiber A. The effects of complex stapes motion on the response of the cochlea in guinea pigs. In: Huber A, Eiber A (eds) Middle Ear Mechanics in Research and Otology. Singapore, World Scientific, pp. 139-144, 2007.

SмYTH GDL. TORPs: how have they fared after five years? J Laryng Otol 97:991-993, 1983.

Sudhoff H, Lindner N, Gronemeyer J, Dazert S, Hildmann H. Study of osteointegration of a titanium prosthesis to the stapes: observations on an accidentally extracted stapes. Otol. Neurotol. 26(4):583-586, 2005.

Tissakht M, Ahmed AM. Tensile stress-strain characteristics of the human meniscal material. J. Biomech. 28(4):411-422, 1995.

Willi UB, Ferrazzini MA, Huber AM. The incudo-malleolar joint and sound transmission losses. Hear. Res. 174(1-2):32-44, 2002.

Woo SL, Akeson WH, Jемmotт GF. Measurements of nonhomogeneous, directional mechanical properties of articular cartilage in tension. J. Biomech. 9(12):785-91, 1976.

ZAHNERT T. Laser in der Ohrforschung. Laryngorhinootologie 82(Suppl 1):157-180, 2003. 